\title{
Fabrication of acrylate monolith using photopolymerization: Effect of light intensity on electrochromatographic performance
}

Yoann Ladner, Gérard Crétier, Karine Faure*

Université de Lyon

Institut des Sciences Analytiques (UMR 5280 Université Lyon 1 / CNRS)

Domaine scientifique de La Doua, bâtiment Curien

43 boulevard du 11 novembre 1918

69622 Villeurbanne cedex

France

*corresponding author

tel +33472431078

fax +33472448319

email karine.faure@univ-lyon1.fr

\section{Abstract}

A hexyl acrylate monolith was prepared via photopolymerization into a cyclic olefin copolymer micro-device for reversed-phase electrochromatography purposes. This work deals with the influence of the irradiation conditions (irradiation time and light intensity) used during synthesis on the electrochromatographic performances of the monolithic column obtained. Up to day, the monolith structure was often controlled by means of irradiation time at constant light intensity, but the effect of light intensity (irradiance) on the monolith structure was scarcely considered. This study shows a strong effect of light intensity on electrochromatographic efficiency. Using an optimal light intensity of $4.7 \mathrm{~mW} / \mathrm{cm}^{2}$ and an irradiation time of a few minutes allows obtaining heights equivalent to a theoretical plate reaching down to $5 \mu \mathrm{m}$ for the reversed-phase separation of six polycyclic aromatic hydrocarbons. 


\section{Keywords}

Cyclic Olefin Copolymer / Acrylate monolith / Photopolymerization / Light intensity / Electrochromatography

\section{Introduction}

Monolithic columns have been intensively developed since the 1990s for different applications [1]. Acrylate- or methacrylate-based monoliths are among the most popular materials used as stationary phase for liquid chromatography and electrochromatography in capillary format and microchip. These porous solids are usually prepared via free-radical polymerization of a mixture consisting of one or more functional monomers in the presence of a binary porogenic solvent. This polymerization process can be initiated thermally or by UVirradiation via the addition of an initiator in the mixture [2]. The main advantages of photopolymerization are the fast and easy preparation of the porous materials and the possibility to localize the monolith inside the separation area $[3,4]$.

The photo-polymerisation process is described by the degree of conversion DC versus time $t$ according to equation [5]:

$$
\mathrm{DC}=1-\exp \left[-\mathrm{k}_{\mathrm{p}} \mathrm{t}\left(\mathrm{P} \Phi_{\mathrm{i}} \varepsilon_{\mathrm{i}} \mathrm{C}_{\mathrm{i}} / \mathrm{k}_{\mathrm{t}}\right)^{1 / 2}\right]
$$

This expression shows that the reaction kinetics depends on : (i) the nature of monomers and porogens (through the rate-constants of chain propagation $\mathrm{k}_{\mathrm{p}}$ and termination $\mathrm{k}_{\mathrm{t}}$ ), (ii) the nature of the photo-initiator (through the quantum yield for initiation $\Phi_{\mathrm{i}}$ and the molar extinction coefficient $\varepsilon_{\mathrm{i}}$ at the wavelength of absorbed radiation) and its concentration $\mathrm{C}_{\mathrm{i}}$, (iii) the irradiation conditions (through the wavelength of light source, the power received per unit area $\mathrm{P}$ (also named light intensity or irradiance) and the irradiation time t). Light intensity is function of the power of light source and varies with the distance between light source and polymerization surface according to the inverse square law [6,7]. The energy $\mathrm{W}$ reaching the surface per unit area is given by the following relationship :

$$
\mathrm{W}=\mathrm{Pt}
$$

Numerous studies were performed, often in capillary format and more scarcely in microchip, to understand the influence of monomer mixture [8-10], porogen composition [11-13] and photo initiator concentration [14] on the monolith structure and its chromatographic performances. On the other hand, the influence of irradiation conditions has never completely 
studied. Irradiation time or energy received per unit area at constant light intensity was extensively used as parameters to control the morphology of monolith in capillary and microchip [15-18]. Optimal energy is generally defined as the energy corresponding to the minimal irradiation time necessary to obtain the monolithic structure without reaching the degradation of monolith under UV irradiation. A too low energy involves a monolith with small nodule size because the polymerization process is stopped during the growth phase [17]. At the contrary, a too high energy can destroy the monolith, as demonstrated by the fact that a detection window in capillary is usually obtained when the monolith is exposed to the UV detection lamp during several hours [15]. The effect of light intensity at constant irradiation time was just mentioned in capillary [19], but never used in microchip to optimize monolith morphology.

The topic of this paper is the complete study of the impact of irradiation conditions on the electrochromatographic performances of a hexyl acrylate monolith anchored to the inner walls of a cyclic olefin copolymer (COC) microfluidic device in one step [20]. Light intensity and irradiation time were simultaneous varied in order to obtain the largest efficiency.

\section{Materials and methods}

Hexyl acrylate (HA), 1,3-butanediol diacrylate (BDDA), 2-acrylamido-2-methyl-1propanesulfonic acid (AMPS) and benzoin methyl ether (BME) were obtained from Acros Organics (Noisy-Le-Grand, France). Ammonium phosphate $\left(\mathrm{NH}_{4} \mathrm{H}_{2} \mathrm{PO}_{4}\right)$, various polycyclic aromatic hydrocarbons (PAH) (anthracene, fluoranthene, pyrene, benzo-a-anthracene, benzoa-pyrene and benzo-k-fluoranthene) and lithium dodecyl sulfate (LiDS) was from SigmaAldrich (Isle-d'Abeau, France). Acetonitrile and ethanol were HPLC-grade from SDS (Peypin, France).

Cyclic olefin copolymer microchips (Topas ${ }^{\circledR}$ 6013) were fabricated by Microfluidic Chipshop $\mathrm{GmbH}$ (Jena, Germany). Microfluidic chips for electrochromatographic separation exhibit only one $81 \mathrm{~mm}$-long, $75 \mu \mathrm{m}$-deep and $75 \mu \mathrm{m}$-wide channel.

The monolith based on HA-BDDA monomers was previously used to separate neutral compounds by electrochromatography in COC microchip [20]. The porogenic mixture was made up of $54 \%$ of ACN, $23 \%$ of ethanol and $23 \%$ of water $(\% \mathrm{w} / \mathrm{w})$. Porogenic mixture was dissolved in monomer mixture containing $66.4 \% \mathrm{w} / \mathrm{w}$ of HA and $33.6 \% \mathrm{w} / \mathrm{w}$ of BDDA. The ratio of monomer to porogenic mixtures was $34.5: 65.5 \mathrm{w} / \mathrm{w}$. AMPS $(0.5 \% \mathrm{w} / \mathrm{w}$ of 
monomers) is added in the polymerization mixture in order to support the electroosmotic flow. The photointiator concentration of BME is fixed at $2.5 \% \mathrm{w} / \mathrm{w}$ of monomers to allow the simultaneous synthesis and anchoring of organic monolith inside COC microchip channel in one step. The polymerization mixture was introduced in the microchannel by pressure using a syringe. The microchip was submitted to a subsequent irradiation at $365 \mathrm{~nm}$. The illumination system used to perform UV irradiation for light intensity varying from 0.3 to $4.7 \mathrm{~mW} / \mathrm{cm}^{2}$ was a Bio-link cross-linker (VWR International, Strasbourg, France) equipped with five 8W UV tubes. Light intensity was adjusted between 0.3 and $1.7 \mathrm{~mW} / \mathrm{cm}^{2}$ by placing the micro-device at $15 \mathrm{~cm}$ from the light source and varying the number of UV tubes from 2 to 5 . For light intensity of 3.0 and $4.7 \mathrm{~mW} / \mathrm{cm}^{2}$, the micro-device was placed at 11 and $2.5 \mathrm{~cm}$ from the five UV tubes, respectively. A Hamamatsu system (Massy, France) was used to initiate the polymerization at $365 \mathrm{~nm}$ with a light intensity of $8.4 \mathrm{~mW} / \mathrm{cm}^{2}$. Energy and light intensity were controlled with an UV radiometer (Vilbert Lourmat, Germany). Channels filled with HA-BDDA monolith were then rinsed with $\mathrm{ACN} /$ water $70 / 30(\mathrm{v} / \mathrm{v})+2 \mathrm{mM} \mathrm{NH}_{4} \mathrm{H}_{2} \mathrm{PO}_{4}+5$ $\mathrm{mM}$ LiDS for $30 \mathrm{~min}$ by applying an electric field of $617 \mathrm{~V} / \mathrm{cm}$ to remove any remaining reactant. A JEOL JSM 6700F scanning electron microscope (SEM) (Tokyo, Japan) was used for observations of the homogeneity of monolith structure and estimations of nodule size. Microchip analyses were monitored by inverted fluorescence microscopic system (IX-71, Olympus, France) equipped with a $100 \mathrm{~W}$ mercury lamp and $330 \mathrm{~nm}$ excitation filter (collection above $400 \mathrm{~nm}$ ) (XF02-2, Omega, USA) for the detection of fluorescent PAH. A CCD camera was combined with NI Vision software (Alliance Vision, France) for detection processing. High-power supply (Micralyne, Canada) was used to apply electric field to the microchannel through platinum electrodes placed in the reservoirs. Sample injection in the separation channel was realized by using the simple direct injection mode introduced in a previous publication [18]. Briefly, a droplet of $2 \mu \mathrm{L}$ of sample is placed in the inlet reservoir. An electric field of $124 \mathrm{~V} / \mathrm{cm}$ is applied for $1 \mathrm{~s}$ to introduce the solutes in the channel. The inlet reservoir is then fully washed with the mobile phase and finally the separation electric field is applied. All system operations were performed with Labview 7.1 (National Instrument, Austin, TX, USA).

Injections of fluoranthene were realized to characterize the electrochromatographic performances of the monolith obtained for each condition of synthesis. Separation field strength was varied from $250 \mathrm{~V} / \mathrm{cm}$ to $740 \mathrm{~V} / \mathrm{cm}$ in order to obtain the Van Deemter curves and to determine the plate height $\mathrm{H}_{\min }$ at optimal velocity. The mobile phase used is $85 / 15$ 
(v/v) ACN/water $+2 \mathrm{mM} \mathrm{NH}_{4} \mathrm{H}_{2} \mathrm{PO}_{4}+5 \mathrm{mM}$ LiDS. The effective separation length is $3 \mathrm{~cm}$. Solute concentration is $33.3 \mu \mathrm{M}$ for fluoranthene.

The electroosmotic mobility $\left(\mu_{\mathrm{eo}}\right)$ in the microchannel was determined using the current monitoring method [21]. Briefly, the channel is first filled with a mobile phase ACN/water $70 / 30(\mathrm{v} / \mathrm{v})+2 \mathrm{mM} \mathrm{NH}_{4} \mathrm{H}_{2} \mathrm{PO}_{4}+5 \mathrm{mM} \mathrm{LiDS}$ by electroomosis. The injection reservoir is then filled with a solution of different ionic strength, ACN/water 70/30 (v/v) $+5 \mathrm{mM}$ $\mathrm{NH}_{4} \mathrm{H}_{2} \mathrm{PO}_{4}+5 \mathrm{mM}$ LiDS and an electric field of $617 \mathrm{~V} / \mathrm{cm}$ is applied. The solution of the injection reservoir flows into the microchannel and after a while the electric current in the circuit has changed. The measure of this time (average of six determinations) allows the calculation of $\mu_{\mathrm{eo}}$ from the applied electric field and the channel length. It is then possible to calculate the retention factor of each solute.

\section{Results and Discussion}

Figure 1 visualizes all the irradiation conditions used for the synthesis of acrylate monolith in the COC micro-channel. For a fixed light intensity $\mathrm{P}$, irradiation energy $\mathrm{W}$ was increased by increasing irradiation time $\mathrm{t}$ (according to equation 2). On the graph $\mathrm{W}$ versus $\mathrm{t}$, these experiments are represented by points situated on a straight line including origin. Seven values of $\mathrm{P}$ were tested (see Materials and Method section). The value placed close to each experiment point states the minimal plate height $\mathrm{H}_{\min }$ obtained for fluoranthene. Irradiation time (consequently, irradiation energy) does not seem to be the major parameter influencing electrochromatography efficiency. Indeed, for a given value of $\mathrm{P}, \mathrm{H}_{\min }$ stays constant until the monolith begins to degrade because irradiation time becomes too long: for example, at $\mathrm{P}=1.7 \mathrm{~mW} / \mathrm{cm}^{2}, \mathrm{H}_{\min }=8-9 \mu \mathrm{m}$ for $\mathrm{t}=7.5,14$ and $20 \mathrm{~min}$ and $\mathrm{H}_{\min }=17 \mu \mathrm{m}$ for $\mathrm{t}$ $=30 \mathrm{~min}$. UV degradation is prejudicial to electrochromatographic performances before it becomes visible on monolithic structure (Figure S2 - Supplementary information).

On the other hand, electrochromatography performance is strongly dependent on light intensity. At $\mathrm{t}=20 \mathrm{~min}, \mathrm{H}_{\min }$ decreases from 60 to $9 \mu \mathrm{m}$ when $\mathrm{P}$ increases from 0.3 to 1.7 $\mathrm{mW} / \mathrm{cm}^{2}$. At W $=1.9 \mathrm{~J} / \mathrm{cm}^{2}, \mathrm{H}_{\min }$ first decreases from 9 to $5 \mu \mathrm{m}$ when $\mathrm{P}$ increases from 1.7 to $4.7 \mathrm{~mW} / \mathrm{cm}^{2}$ and then increases to $18 \mu \mathrm{m}$ when $\mathrm{P}$ reaches $8.4 \mathrm{~mW} / \mathrm{cm}^{2}$. So, there is an optimal light intensity $\left(4.7 \mathrm{~mW} / \mathrm{cm}^{2}\right.$ ) for which $\mathrm{H}_{\min }$ is minimal (equal to $5 \mu \mathrm{m}$ ) i.e. 
electrochromatography efficiency is maximal $(\mathrm{N}=200000$ plates $/ \mathrm{m})$. The irradiation time needed to achieve this performance is very short: $2 \mathrm{~min}$ are sufficient.

The increase of light intensity also involves a modification of monolith morphology (SEM images are provided as supporting information). Nodule size decreases from 0.9 to $0.7 \mu \mathrm{m}$ when light intensity increases from 1.2 to $4.7 \mathrm{~mW} / \mathrm{cm}^{2}$, and then increases to $1.4 \mu \mathrm{m}$ for $\mathrm{P}=$ $8.4 \mathrm{~mW} / \mathrm{cm}^{2}$ (Figure S1). These observations are corroborated by the modification of van Deemter curves of fluoranthene with P-value (Figure 2): the contributions of stationary phase inhomogeneity and mass transfer between mobile and stationary phase seem to be minimal when the nodule size is minimized. Irradiation conditions that resulted in highly homogeneous structures $\left(\mathrm{P}=1.7 \mathrm{~mW} / \mathrm{cm}^{2}\right.$ and $\mathrm{P}=4.7 \mathrm{~mW} / \mathrm{cm}^{2}$, Figure $\left.\mathrm{S} 1\right)$ provide a efficient stationary phase with a flat van Deemter profile (Figure 2). An optimal light intensity of $4.7 \mathrm{~mW} / \mathrm{cm}^{2}$ results in minimal height of a theoretical plate. Although the differences between the polymeric structures obtained at $1.7 \mathrm{~mW} / \mathrm{cm}^{2}$ and $4.7 \mathrm{~mW} / \mathrm{cm}^{2}$ are not very important, it can be observed that the optimal intensity corresponds to 1$)$ the smallest nodule size $(0.7 \mu \mathrm{m}) ; 2)$ discrete nodules and absence of agglomerates (Figure S1). As light intensity increases, the decrease of nodule size can be attributed to an increase in polymerization rate. The amount of free radical nuclei is increased and their molecular mobility is also increased because of the increase of temperature with light intensity [22]. Consequently, polymerization process starts in more places and a great number of small nodules are formed. At very high light intensity $\left(8.4 \mathrm{~mW} / \mathrm{cm}^{2}\right)$, the concentration of nuclei is so high that polymerization reaction proceeds in both growing nodules and surrounding solution. This involves the formation of larger agglomerates (visible on Figure S1) which are composed of embedded smaller nodules [19]. This led to inhomogeneous sizes in the range of 0.8-1.4 $\mu \mathrm{m}$.

For low intensity, the van Deemter curve reflects a large B-term. We suppose that this is due to voids in the polymeric structure that reduce the obstruction term. If the SEM analysis at 1.2 $\mathrm{mW} / \mathrm{cm}^{2}$ did not visibly point these voids, the experiments conducted at even lower intensity $\left(0.6 \mathrm{~mW} / \mathrm{cm}^{2}\right.$ and $\left.0.3 \mathrm{~mW} / \mathrm{cm}^{2}\right)$ increased this phenomenon and defects become visible on SEM images (Figure S3). B-term is enhanced so that the optimal plate heights obtained at low intensities were in the range 40-60 $\mu \mathrm{m}$ (van Deemter curves exhibited in supplementary material, Figure S4).

The effect of irradiation energy and light intensity on electroosmotic mobility is illustrated in Figure 3A. Electroosmotic mobility is increased by $30 \%$ when irradiation energy increases 
from 0.7 to $1.9 \mathrm{~J} / \mathrm{cm}^{2}$ and keeps constant when irradiation energy is above of $1.9 \mathrm{~J} / \mathrm{cm}^{2}$. This is due to the fact that charged monomers AMPS responsible for EOF generation, are not fully converted with energy lower than $1.9 \mathrm{~J} / \mathrm{cm}^{2}$. As already observed in the literature [10, 13], a minimal irradiation energy is necessary to incorporate all AMPS monomers in the monolith structure. Figure 3B shows the influence of irradiation energy and light intensity on retention factor of fluoranthene. In the range of irradiation conditions considered (W $=0.7$ to $2.5 \mathrm{~J} / \mathrm{cm}^{2}$ and $\mathrm{P}=1.7$ to $4.7 \mathrm{~mW} / \mathrm{cm}^{2}$ ), the retention factor of fluoranthene seems to be constant. This result indicates that the total conversion of uncharged monomers HA and BDDA can be very fast: the irradiation time corresponding to $\mathrm{W}=0.7 \mathrm{~J} / \mathrm{cm}^{2}$ at $\mathrm{P}=4,7 \mathrm{~mW} / \mathrm{cm}^{2}$ is $2 \mathrm{~min}$. This is due to the high reactivity of acrylate monomers in polymerization process under $\mathrm{UV}$ irradiation [22].

The separation of six PAH included in the United States Environmental Protection Agency list of priority organic pollutants [23] illustrates the high separation efficiency ( $\mathrm{N}=200000$ to 250000 plates $/ \mathrm{m}$ for every solute) obtained with the hexyl acrylate monolith photopolymerized in COC microchip with an energy of $1.9 \mathrm{~J} / \mathrm{cm}^{2}$ and an intensity of $4.7 \mathrm{~mW} / \mathrm{cm}^{2}$ (Figure 4). All solutes are separated in less than $3.5 \mathrm{~min}$ on a separation length of $2 \mathrm{~cm}$. This separation was achieved on 5 microchips obtained with 5 polymerization mixtures having identical composition but prepared separately. The batch-to-batch repeatability of monolith synthesis is quite satisfactory since the relative standard deviation for the column efficiency, retention factor and electroosmotic mobility is 6,8 and $10 \%$, respectively. In order to evaluate the injection-to-injection repeatability, the six PAH sample was injected 4 times in each monolithic column. The relative standard deviation calculated is $8 \%$ for column efficiency and $7 \%$ for retention factor.

\section{Concluding remarks}

The influence of irradiation time (or irradiation energy at constant light intensity) on the structure and chromatographic performances of acrylate monoliths obtained by photopolymerization, was widely studied. We demonstrate in this work that the choice of light intensity is very important to get an efficient acrylate monolithic stationary phase in COC microchip. For our system, the adjustment of light intensity to $4.7 \mathrm{~mW} / \mathrm{cm}^{2}$ results in column efficiency of $200000-250000$ plates $/ \mathrm{m}$. Controlling every polymerization parameters will lead to more reliable monoliths and hence an extended use of electrochromatography on chip. 
The one-step process for the simultaneous synthesis and anchoring of organic monolith inside COC microchip channel is under French patent pending $n^{\circ} 1156586$.

\section{References}

[1] Svec F., J. Chromatogr. B, 2006, $\underline{841}, 52-64$.

[2] Svec F., Electrophoresis, 2009, 30, S68-S82.

[3] Faure K., Albert M., Dugas V., Crétier G., Ferrigno R., Morin P., Rocca J. L., Electrophoresis, 2008, 29, 4948-4955.

[4] Flook K., Agroskin Y., Pohl C., J. Sep. Sci., 2011, 34, 2047-2053.

[5] Watts D. C., Dent Mater, 2005, 21, 27-35.

[6] Calvert J. G., Pitts Jr J. N., Thompson D. D., J. Am. Chem. Soc., 1956, 78, 4239-4242.

[7] Van Gerven T., Mul G., Moulijn J., Stankiewicz A., Chem. Eng. Process., 2007, 46, 781-789.

[8] Viklund C., Svec F., Frechet J. M. J., Irgum K., Chem. Mater., 1996, $\underline{8}$, 744-750.

[9] Zhang L., Ping G., Zhang L., Zhang W., Zhang Y., J. Sep. Sci., 2003, 26, 331-336.

[10] Yu C., Xu M., Svec F., Fréchet J. M. J., J. Polym. Sci., Part A: Polym. Chem., 2002,

Mis en forme : Français 40, 755-769.

[11] Svec F., Frechet J. M. J., Chem. Mater., 1995, 7, 707-715.

[12] Grafnetter J., Coufal P., Tesařová E., Suchánková J., Bosáková Z., Ševčik J., J. Chromatogr. A, 2004, 1049, 43-49.

[13] Yu C., Svec F., Frechet J. M. J., Electrophoresis, 2000, 21, 120-127.

[14] Bernabé-Zafón V., Beneito-Cambra M., Simó-Alfonso E. F., Herrero-Martínez J. M., J. Chromatogr. A, 2010, 1217, 3231-3237.

[15] Augustin V., Jardy A., Gareil P., Hennion M. C., J. Chromatogr. A, 2006, 1119, 8087.

[16] Bernabé-Zafón V., Beneito-Cambra M., Simó-Alfonso E. F., Ramis-Ramos G., Herrero-Martínez J. M., Electrophoresis 2009, 30, 1929-1936.

[17] Barrioulet M. P., Delaunay-Bertoncini N., Demesmay C., Rocca J. L., Electrophoresis, 2005, 26, 4104-4115.

[18] Ladner Y., Crétier G., Faure K., J. Chromatogr. A, 2010, 1217, 8001-8008.

[19] Eeltink S., Hilder E. F., Geiser L., Svec F., Fréchet J. M. J., Rozing G. P., Schoenmakers P. J., Kok W. T., J. Sep. Sci., 2007, 30, 407-413. 
[20] Ladner Y., Bruchet A., Crétier G, Dugas V, Randon J, Faure K., Lab Chip, 2012, 12 , 1680-1685.[21] Huang X., Gordon M. J., Zare R. N., Anal. Chem., 1988, 60, 1837-

1838 .

[22] Decker C., Polym.Int., 1998, 45, 133-141.

[23] Plaza-Bolaños P., Frenich A. G., Vidal J. L. M., J. Chromatogr. A, 2010, 1217, 63036326. 


\section{Figure Captions:}

Figure 1 : Influence of light intensity $\mathrm{P}$ and irradiation time $\mathrm{t}$ (or irradiation energy $\mathrm{W}$ ) on minimal plate height $\mathrm{H}_{\min }(\mu \mathrm{m})$ for fluoranthene.

Figure 2: Van Deemter curves obtained for fluoranthene with $1.9 \mathrm{~J} / \mathrm{cm}^{2}$ irradiation energy and different light intensities.

Figure 3 : Influence of irradiation energy $\mathrm{W}$ on (A) electroosmotic mobility and (B) retention factor of fluoranthene. Mobile phase : ACN/water 85/15 (v/v) $+2 \mathrm{mM} \mathrm{NH}_{4} \mathrm{H}_{2} \mathrm{PO}_{4}+5 \mathrm{mM}$ LiDS. Monolith synthesized at optimal light intensity $\mathrm{P}=4.7 \mathrm{~mW} / \mathrm{cm}^{2}$.

Figure 4: Reversed-phase electrochromatographic separation of six PAHs on acrylate monolith in COC microchip. Mobile phase: ACN/water 70/30 (v/v) $+2 \mathrm{mM} \mathrm{NH}_{4} \mathrm{H}_{2} \mathrm{PO}_{4}+5$ mM LiDS. Separation field strength: $740 \mathrm{~V} / \mathrm{cm}$. Separation length: $2 \mathrm{~cm}$. Sample composition: (1) anthracene (120 $\mu \mathrm{M})$, (2) fluoranthene (33.3 $\mu \mathrm{M})$, (3) pyrene (430 $\mu \mathrm{M})$, (4) benzo-a-anthracene $(0.33 \mu \mathrm{M})$, (5) benzo-a-pyrene $(8.8 \mu \mathrm{M})$, (6) benzo-k-fluoranthene (4.4 $\mu \mathrm{M})$.

\section{Supplementary informations:}

Figure S1 : SEM images of an acrylate monolith obtained at $\mathrm{W}=1.9 \mathrm{~J} / \mathrm{cm}^{2}$ for different light intensity $\mathrm{P}$

Figure $\mathrm{S} 2$ : SEM images of an acrylate monolith obtained at $\mathrm{P}=1.7 \mathrm{~mW} / \mathrm{cm}^{2}$

(A) for $\mathrm{W}=1.9 \mathrm{~J} / \mathrm{cm}^{2}$, (B) for $\mathrm{W}=2.9 \mathrm{~J} / \mathrm{cm}^{2}$ and (C) for $\mathrm{W}=6 \mathrm{~J} / \mathrm{cm}^{2}$.

(D) the acrylate monolith was obtained for $\mathrm{W}=2.5 \mathrm{~J} / \mathrm{cm}^{2}$ at $\mathrm{P}=3 \mathrm{~mW} / \mathrm{cm}^{2}$.

Figure S3 : SEM images of an acrylate monolith obtained after $20 \mathrm{~min}$ of low intensity photopolymerization . (A) for $\mathrm{W}=0.4 \mathrm{~J} / \mathrm{cm}^{2}$ et $\mathrm{P}=0.3 \mathrm{~mW} / \mathrm{cm}^{2}$ and (B) for $\mathrm{W}=0.8 \mathrm{~J} / \mathrm{cm}^{2}$ et $\mathrm{P}=0.6 \mathrm{~mW} / \mathrm{cm}^{2}$.

Figure S4: van Deemter curve obtained for fluoranthene with a monolith synthesized with a $20 \mathrm{~min}$ irradiation time at different light intensities. 


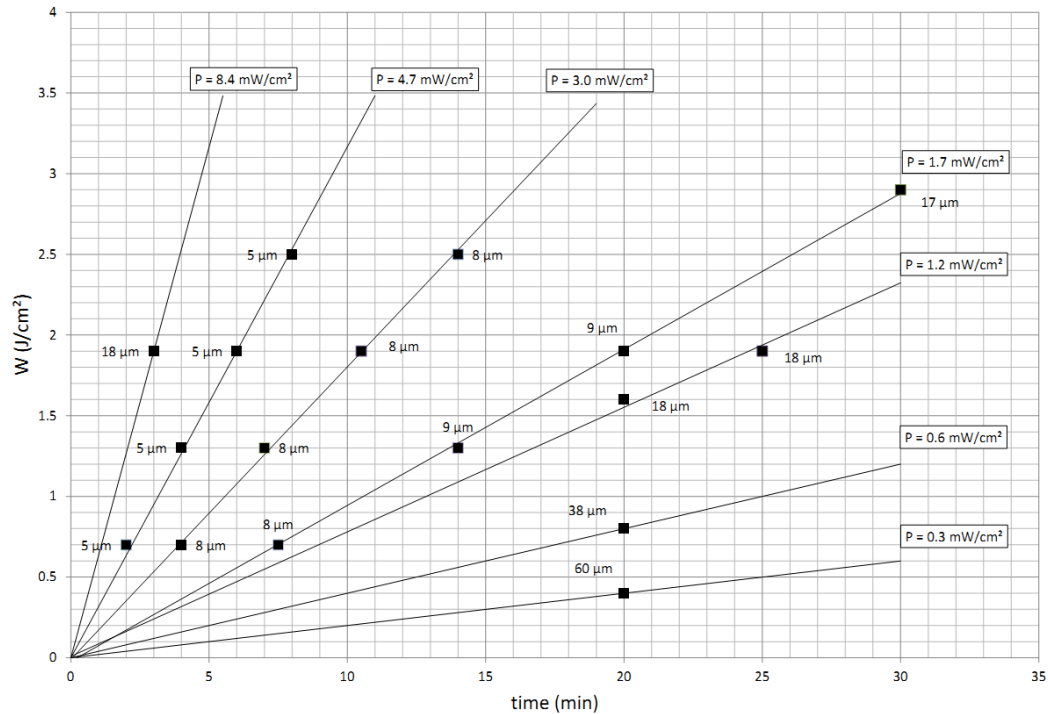

Figure 1 : Influence of light intensity P and irradiation time t (or irradiation energy $\mathrm{W}$ ) on minimal plate height $\mathrm{H}_{\min }(\mu \mathrm{m})$ for fluoranthene.

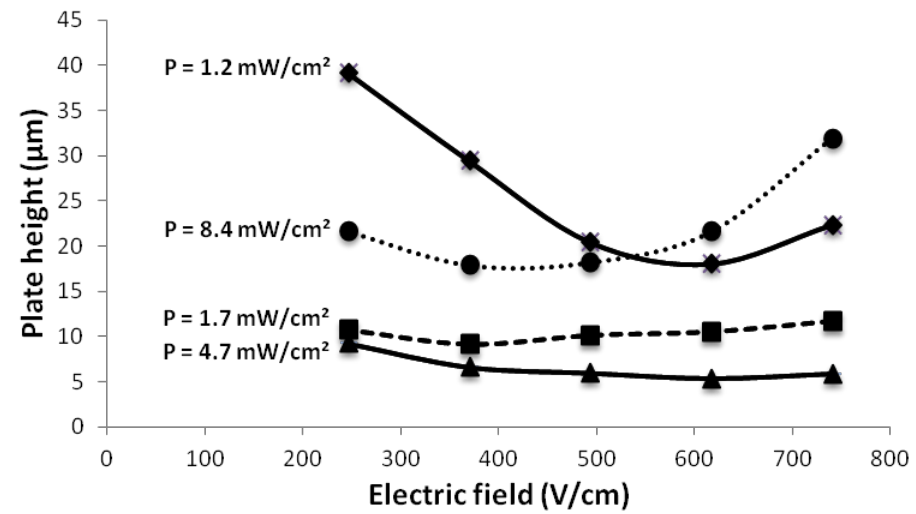

Figure2 : Van Deemter curves obtained for fluoranthene with $1.9 \mathrm{~J} / \mathrm{cm}^{2}$ irradiation energy and different light intensities. 


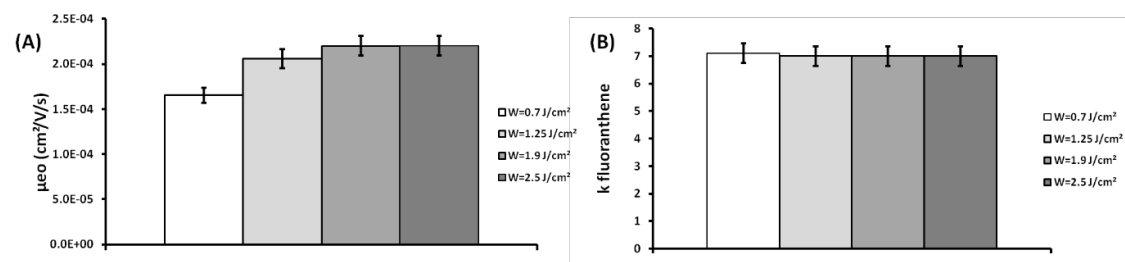

Figure 3 : Influence of irradiation energy W (A) on electroosmotic mobility and (B) retention factor of fluoranthene with a light intensity of $4.7 \mathrm{~mW} / \mathrm{cm}^{2}$. Mobile phase : ACN/water $85 / 15(\mathrm{v} / \mathrm{v})+2 \mathrm{mM}$ $\mathrm{NH}_{4} \mathrm{H}_{2} \mathrm{PO}_{4}+5 \mathrm{mM}$ LiDS.

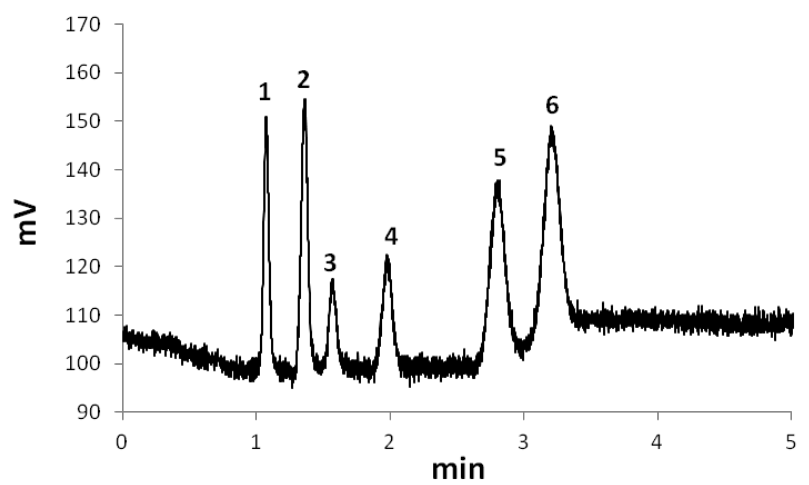

Figure 4 : Reversed-phase electrochromatographic separation of six PAHs on acrylate monolith in $\mathrm{COC}$ microchip. Mobile phase : ACN/water 70/30 (v/v) $+2 \mathrm{mM} \mathrm{NH}_{4} \mathrm{H}_{2} \mathrm{PO}_{4}+5 \mathrm{mM}$ LiDS. Separation field strength : $740 \mathrm{~V} / \mathrm{cm}$. Separation length : $2 \mathrm{~cm}$. Sample composition : (1) anthracene $(120 \mu \mathrm{M}),(2)$ fluoranthene $(33.3 \mu \mathrm{M})$, (3) pyrene $(430 \mu \mathrm{M})$, (4) benzo-a-anthracene $(0.33 \mu \mathrm{M})$, (5) benzo-a-pyrene $(8.8 \mu \mathrm{M}),(6)$ benzo-k-fluoranthene $(4.4 \mu \mathrm{M})$. 


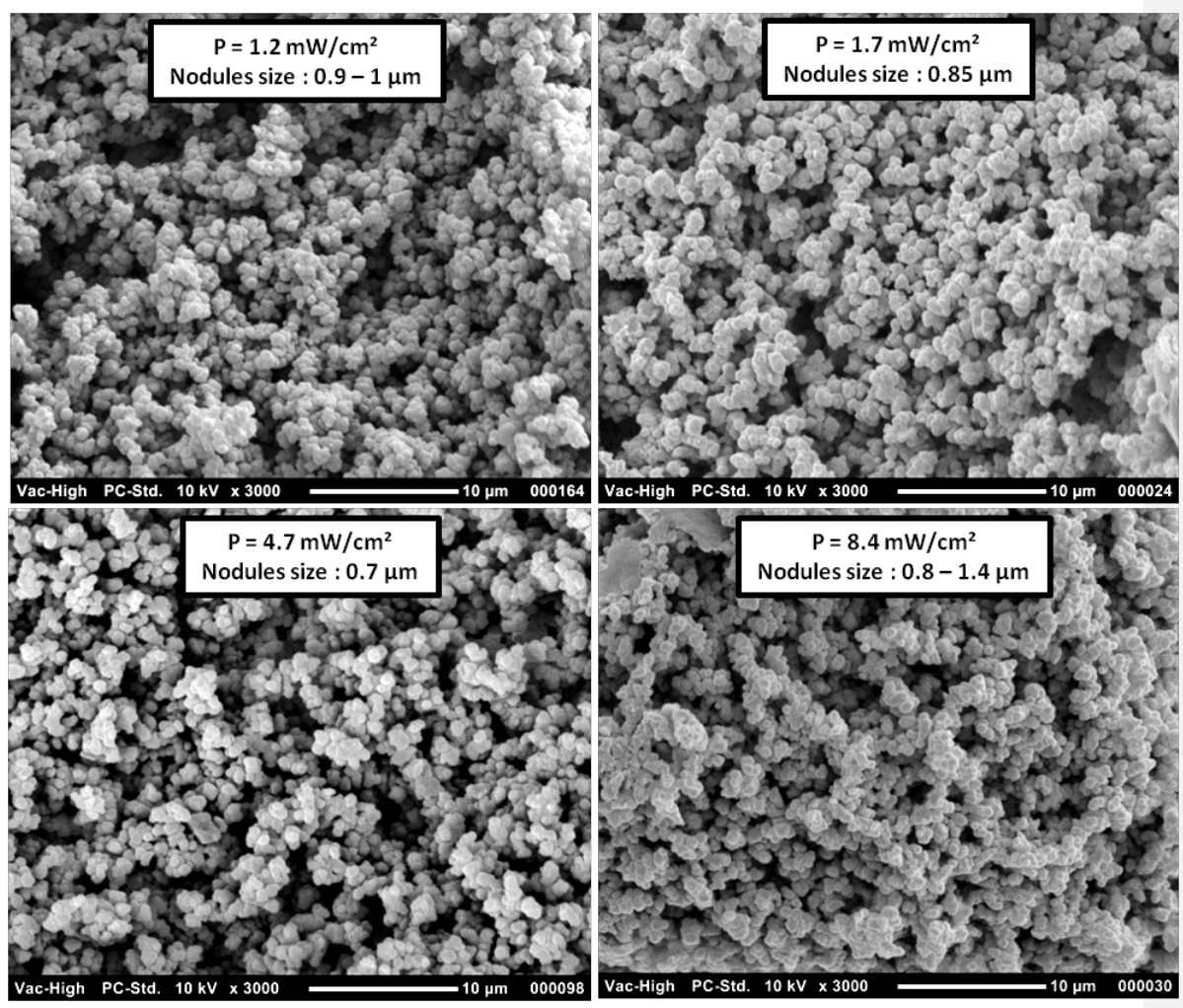

Figure S1 : SEM images of an acrylate monolith obtained at $\mathrm{W}=1.9 \mathrm{~J} / \mathrm{cm}^{2}$ for different light intensity $\mathrm{P}$ 

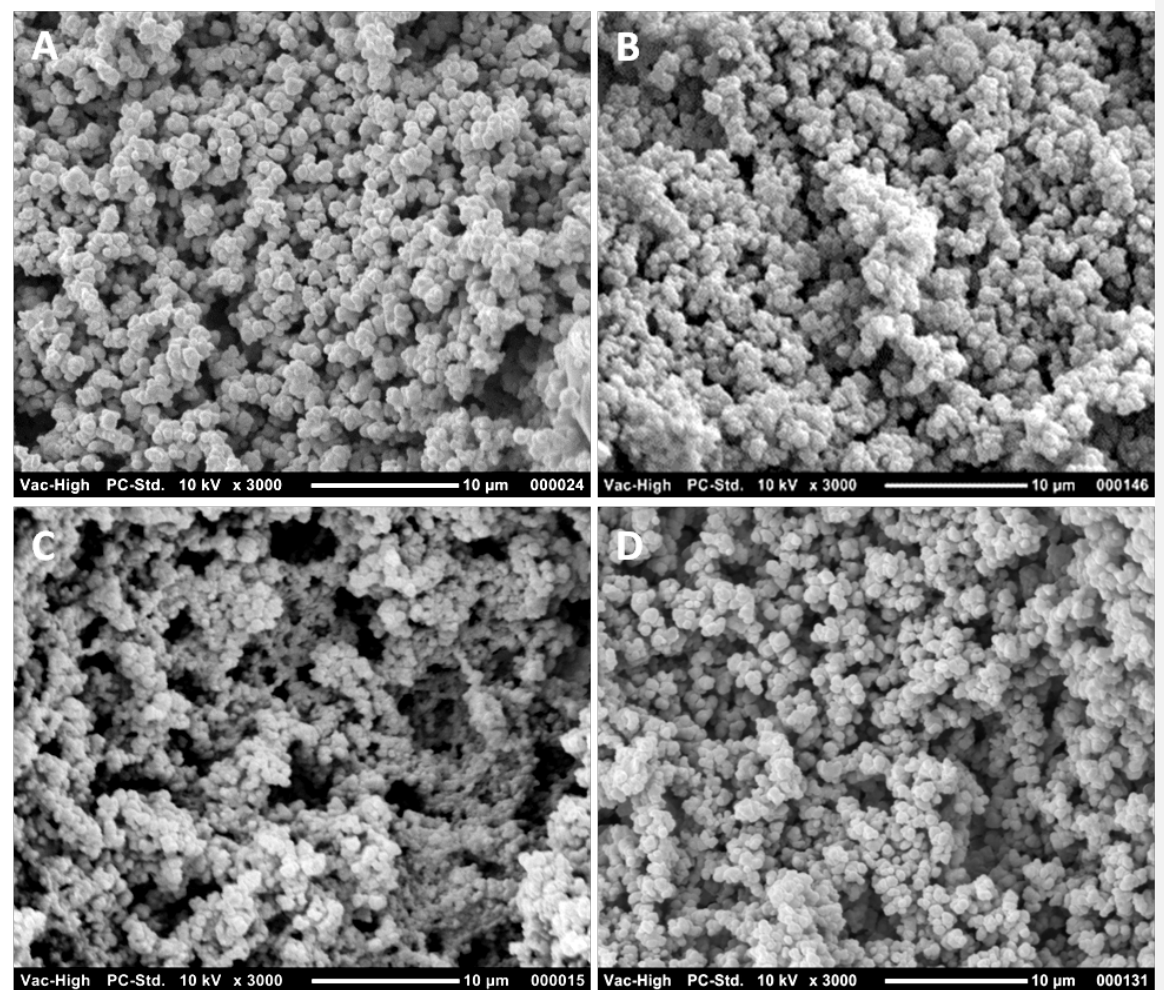

Figure $\mathrm{S} 2$ : SEM images of an acrylate monolith obtained at $\mathrm{P}=1.7 \mathrm{~mW} / \mathrm{cm}^{2}$

(A) for $\mathrm{W}=1.9 \mathrm{~J} / \mathrm{cm}^{2}$, (B) for $\mathrm{W}=2.9 \mathrm{~J} / \mathrm{cm}^{2}$ and (C) for $\mathrm{W}=6 \mathrm{~J} / \mathrm{cm}^{2}$.

(D) the acrylate monolith was obtained for $\mathrm{W}=2.5 \mathrm{~J} / \mathrm{cm}^{2}$ at $\mathrm{P}=3 \mathrm{~mW} / \mathrm{cm}^{2}$.

\section{Commentaries on UV degradation}

Degradation of monoliths under long-term UV exposure is well known as stated in the introduction.

Once again, the observations using SEM reflect this degradation when it reaches the macroscopic level. However, the collapse is observable through electrochromatographic performances long before it appears on SEM pictures. To illustrate this degradation, we provide to the readers the evolution of the macroscopic structure of a monolith synthesized with $\mathrm{P}=1.7 \mathrm{~mW} / \mathrm{cm}^{2}$ over $20 \mathrm{~min}$ (Figure S2A), 30min (Figure S2B) and $60 \mathrm{~min}$ (Figure S2C).

It appears from the electrochromatographic performances that the monolith is degraded under $30 \mathrm{~min}$ at $1.7 \mathrm{~mW} / \mathrm{cm}^{2}$ (Figure S2B), whereas it is still efficient when synthesized under $14 \mathrm{~min}$ irradiation at $3.0 \mathrm{~mW} / \mathrm{cm}^{2}$ (Figure S2D), meaning that the energy received (over $2.5 \mathrm{~J} / \mathrm{cm}^{2}$ ) is not the main cause of degradation. This degradation is not so clear on SEM observations. 


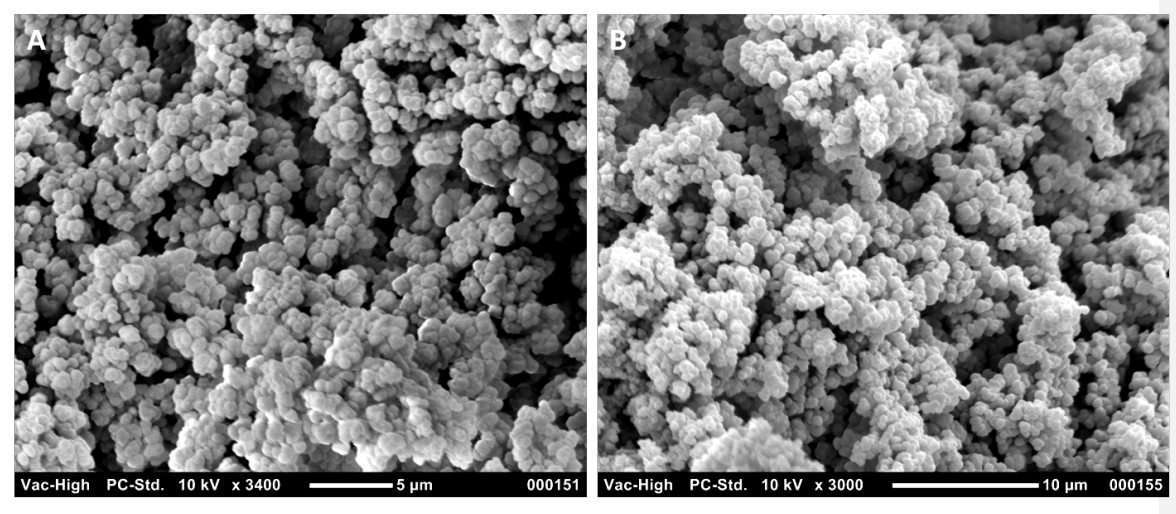

Figure S3 : SEM images of an acrylate monolith obtained after $20 \mathrm{~min}$ of

photopolymerization (A) for $\mathrm{W}=0.4 \mathrm{~J} / \mathrm{cm}^{2}$ et $\mathrm{P}=0.3 \mathrm{~mW} / \mathrm{cm}^{2}$ and (B) for $\mathrm{W}=0.8 \mathrm{~J} / \mathrm{cm}^{2}$ et $\mathrm{P}$ $=0.6 \mathrm{~mW} / \mathrm{cm}^{2}$. 